\title{
Work Productivity in Scleroderma: Analysis From the University of California, Los Angeles Scleroderma Quality of Life Study
}

\author{
MANJIT K. SINGH, ${ }^{1}$ PHILIP J. CLEMENTS, ${ }^{2}$ DANIEL E. FURST, ${ }^{2}$ PAUL MARANIAN, ${ }^{2}$ \\ AND DINESH KHANNA ${ }^{3}$
}

Objective. To examine the productivity of patients with scleroderma (systemic sclerosis [SSc]) both outside of and within the home in a large observational cohort.

Methods. One hundred sixty-two patients completed the Work Productivity Survey. Patients indicated whether or not they were employed outside of the home, how many days per month they missed work (employment or household work) due to SSc, and how many days per month productivity was decreased by $\geq 50 \%$. Patients also completed other patient-reported outcome measures. We developed binomial regression models to assess the predictors of days missed from work (paid employment or household activities). The covariates included: type of SSc, education, physician and patient global assessments, Health Assessment Questionnaire (HAQ) disability index (DI), Functional Assessment of Chronic Illness Therapy-Fatigue, and Center of Epidemiologic Studies Depression Scale Short Form.

Results. The mean age of patients was 51.8 years and $52 \%$ had limited cutaneous SSc. Of the $37 \%$ of patients employed outside of the home, patients reported missing 2.6 days per month of work and had 2.5 days per month of productivity reduced by half. Of the 102 patients who were not employed, $39.4 \%$ were unable to work due to their SSc. When we assessed patients for household activities $(n=162)$, patients missed an average of 8 days of housework per month and had productivity reduced by an average of 6 days per month. In the regression models, patients with lower education and poor assessment of overall health by a physician were more likely to miss work outside of the home. Patients with limited cutaneous SSc and high HAQ DI scores were more likely to miss work at home.

Conclusion. SSc has a major impact on productivity at home and at work. Nearly $40 \%$ of patients reported disability due to their SSc.

\section{INTRODUCTION}

Systemic sclerosis (SSc; scleroderma) can be associated with functional disability and internal organ damage (1). SSc causes substantial economic burden as assessed by direct and indirect costs related to SSc $(1,2)$. Previous studies have largely focused on work disability associated

The University of California, Los Angeles Scleroderma Quality of Life Study was supported by grants from the NIH (National Institute of Arthritis and Musculoskeletal and Skin Diseases) and the Scleroderma Foundation. Dr. Khanna's work was supported by the National Institute of Arthritis and Musculoskeletal and Skin Diseases (grant K23AR053858-05).

${ }^{1}$ Manjit K. Singh, MD: Rochester General Health System, Rochester, New York; ${ }^{2}$ Philip J. Clements, MD, MPH, Daniel E. Furst, MD, Paul Maranian, MS: David Geffen School of Medicine, University of California, Los Angeles; ${ }^{3}$ Dinesh Khanna, MD, MSc: University of Michigan Scleroderma Program, Ann Arbor.

Dr. Clements has received consultant fees, speaking fees, and/or honoraria (less than $\$ 10,000$ ) from Gilead. with SSc $(3,4)$. However, many patients continue to work despite their SSc and may require taking days off or reducing their productivity at work due to illness flare or medical appointments (5). Work productivity assesses the economic productivity of a person, described in terms of costs, profits, or output targets (5), and has an impact on the individual, the employer, and society. It can be further divided into absenteeism (full days of work missed due to disability) and presenteeism (days with work productivity reduced by $\geq 50 \%$ ) (5-7). In addition, productivity assesses the impact of an illness on a patient's ability to do household activities.

Address correspondence to Dinesh Khanna, MD, MSc, University of Michigan Scleroderma Program, Division of Rheumatology/Department of Internal Medicine, 24 Frank Lloyd Wright Drive, Lobby M, Suite 2500, SPC 5753, PO Box 481, Ann Arbor, MI 48106. E-mail: khannad@med.umich. edu.

Submitted for publication March 8, 2011; accepted in revised form October 7, 2011. 


\section{Significance \& Innovations}

- Systemic sclerosis (SSc; scleroderma) has a major impact on productivity at home and at work.

- Approximately $40 \%$ of patients are disabled due to their SSc in a large observational cohort.

Participants of Outcome Measures in Rheumatology 9 (OMERACT 9) strongly endorsed work productivity as an outcome measure in different arthritides (5). The Work Productivity Survey-Rheumatoid Arthritis (WPS-RA) is a validated instrument that was initially developed for rheumatoid arthritis (RA) (8) and has been used in a longitudinal clinical trial in RA (7). The self-reported questionnaire is based on self-report with a recall period of 1 month and assesses productivity at work and at home (8). The WPS-RA was found to meet OMERACT filters of truth, discrimination, and feasibility at the OMERACT 9 conference (5). We assessed productivity outside of and within the home using the modified WPS-RA in a large observational study in patients with SSc. The objectives of this study were to 1) assess the prevalence of productivity outside of and within the home in patients with SSc, 2) determine the predictors of decreased productivity outside of and within the home in SSc, and 3) assess the prevalence and predictors of self-reported SSc-associated disability.

\section{PATIENTS AND METHODS}

Patient sample. One hundred sixty-two participants with SSc participated in the University of California, Los Angeles (UCLA) Scleroderma Quality of Life study (9). The participants are patients who were evaluated for their SSc at the UCLA Scleroderma Program. Patients underwent clinical history and physical examination to determine the type of SSc (limited cutaneous SSc [lcSSc], diffuse cutaneous SSc [dcSSc], or overlap syndrome) and physician global assessment. Patients completed sociodemographic information (age, sex, ethnicity, and level of education), the patient global assessment, and the WPS. All data were gathered at the same visit for each patient.

Patient-reported measures. The WPS-RA (8) was initially developed for RA. We modified the survey by replacing the word "arthritis" with "scleroderma" throughout the survey so that we could assess the impact of SSc on productivity within and outside of the home in terms of daily activities. The survey is based on self-report, with a recall period of 1 month. It consists of 9 questions. The first question assesses employment status, type of job for the employed (nonmanual, manual, or mixed manual/nonmanual), and the status of those unemployed (homemaker, retired, student, unable to work due to SSc, unable to work due to non-SSc health problems, or other, i.e., volunteer). The next 3 questions only apply to employed patients and assess absenteeism (full days of work missed due to SSc), presenteeism (days with work productivity reduced by $\geq 50 \%$ ), and how much SSc interfered with work productivity on a scale of $0-10$, where $0=$ "no interference" and 10 = "complete interference."

The last 5 questions of the survey are applicable to all patients and assess productivity limitations at home doing household work (2 questions) and participation in family, social, or leisure activities (3 questions). The WPS makes the assumption that all patients, employed or not employed, participate in household work. Patients are asked the following: number of days with no household work done due to SSc; number of days home productivity was reduced by $\geq 50 \%$ due to SSc; number of days of family, social, or leisure activities that were missed due to SSc; number of days outside hired help (i.e., housekeeper) was needed; and how much SSc interfered with household productivity on a scale of $0-10$, where $0=$ "no interference" and 10 = "complete interference."

The Center for Epidemiologic Studies Short Depression Scale Short Form (CES-D-10) is a 10-item instrument that assesses depressive symptoms (10). The occurrence of each depressive symptom during the past week is rated on a scale from $0-3$, with the total score ranging from $0-30$. A score of $\geq 10$ is indicative of depressed mood. The 10 -item short form was used because it has shown good predictive accuracy when compared to the full-length questionnaire (10) and has been used in SSc studies (9).

The Health Assessment Questionnaire (HAQ) disability index (DI) is a self-reported 20-item musculoskeletal-targeted questionnaire that assesses the impact of disease on physical function and disability (11). The questionnaire contains 20 items divided into 8 domains that measure dressing and grooming, arising, eating, walking, hygiene, reach, and grip, and common daily activities. Patients indicate the degree of difficulty they had in the past week in each of the domains on a scale of 0 (without difficulty) to 3 (unable to do). HAQ DI scores from 0-1 represent no to mild functional difficulty, 1-2 represent moderate functional difficulty, and 2-3 indicate severe functional difficulty (12).

The Functional Assessment of Chronic Illness TherapyFatigue (FACIT-F) is a 13-item questionnaire that assesses fatigue severity and impact on a scale of $0-4$. Total scores range from $0-52$; lower scores indicate more severe fatigue (13).

The patient overall health assessment is a 1-item question that assesses general health status by asking patients, "In general, how would you say your health is?" Responses are rated on a scale of $1-5$, where $1=$ "excellent" health and $5=$ "poor" health. The physician assessment of overall health is a 1-item question that assesses the overall health of a patient in the last week. Physicians are asked, "On a scale of $0-10$, how was your patient's overall health in the last week?" Responses are rated on a scale of 0-10, where $0=$ "excellent" health and $10=$ "extremely poor" health.

Statistical analysis. Mean \pm SD scores and proportions were calculated for all instruments. Days missed at work and days missed at home were treated as count data and 


\begin{tabular}{|c|c|c|c|}
\hline Variables & $\begin{array}{c}\text { Total sample } \\
\quad(n=162)\end{array}$ & $\begin{array}{c}\text { lcSSc } \\
(n=84)\end{array}$ & $\begin{array}{c}\text { dcSSc } \\
(n=67)\end{array}$ \\
\hline Age, mean \pm SD years & $51.8 \pm 14.2$ & $56.0 \pm 14.1$ & $48.3 \pm 12.9+$ \\
\hline Female sex, no. (\%) & $131(81)$ & $70(83.3)$ & $51(76.1)$ \\
\hline \multicolumn{4}{|l|}{ Type of SSc, no. (\%) } \\
\hline lcSSc & $84(51.9)$ & & \\
\hline dcSSc & $67(41.4)$ & & \\
\hline Overlap & $11(6.8)$ & & \\
\hline Disease duration, mean \pm SD years & $7.6 \pm 8.2$ & $9.3 \pm 9.1$ & $5.6 \pm 6.8+$ \\
\hline \multicolumn{4}{|l|}{ Race, no. (\%)‡ } \\
\hline White & $110(69.1)$ & $64(79.0)$ & $40(60.0)$ \\
\hline African American & $10(6.3)$ & $3(3.7)$ & $7(10.5)$ \\
\hline Asian & $21(13.2)$ & $6(7.4)$ & $14(21.0)$ \\
\hline American Indian/Alaskan native & $4(2.5)$ & $3(3.7)$ & $0(0)$ \\
\hline More than one & $10(6.3)$ & $4(4.9)$ & $4(6.0)$ \\
\hline Unknown & $4(2.5)$ & $1(1.3)$ & $2(3)$ \\
\hline \multicolumn{4}{|l|}{ Education, no. (\%) } \\
\hline Grade 8 or less & $5(3.1)$ & $1(1.2)$ & $4(6.0)$ \\
\hline Grade 9-11 & $2(1.3)$ & $0(0)$ & $1(1.5)$ \\
\hline High school graduate & $18(11.3)$ & $11(13.4)$ & $7(10.5)$ \\
\hline Some college & $56(35)$ & $30(36.6)$ & $22(32.8)$ \\
\hline College graduate & $36(22.5)$ & $17(20.7)$ & $17(25)$ \\
\hline One or more years postcollege & $43(26.9)$ & $23(28)$ & $16(24)$ \\
\hline CES-D-10 score, mean \pm SD (range $0-30) \S$ & $8.4 \pm 5.9$ & $8.1 \pm 6.6$ & $8.7 \pm 5.1$ \\
\hline Depressed mood (CES-D score $\geq 10$ ), no. (\%) & $58(35.4)$ & $24(29.0)$ & $28(41.8)$ \\
\hline HAQ DI score, mean \pm SD (range $0-3) \S$ & $0.9 \pm 0.7$ & $0.7 \pm 0.6$ & $1.2 \pm 0.7+$ \\
\hline FACIT-F score, mean \pm SD (range 0-52)II & $31.7 \pm 12.6$ & $34.2 \pm 12.1$ & $28.6 \pm 12.8$ \\
\hline \multicolumn{4}{|c|}{$\begin{array}{l}\text { * }{ }_{\mathrm{cSSC}}=\text { limited cutaneous systemic sclerosis; } \mathrm{dcSSc}_{\mathrm{c}}=\text { diffuse cutaneous systemic sclerosis; CES-D-10 = Center for Epidemiologic Studies } \\
\text { Depression Scale Short Form; HAQ = Health Assessment Questionnaire; DI = disability index; FACIT-F = Functional Assessment of Chronic Illness } \\
\text { Therapy-Fatigue Scale. } \\
+P<0.05 . \\
\text { ‡ One patient with missing data. } \\
\text { § Higher score denotes poor health-related quality of life (HRQOL). } \\
\text { I Lower score denotes poor HRQOL. }\end{array}$} \\
\hline
\end{tabular}

modeled using negative binomial regression. Negative binomial regression is a more flexible alternative to Poisson regression, which requires that the variance of the outcome measure at each fixed level of the covariates be equal to the mean (14). Variables that may be associated with loss of productivity at home and outside of the home were included in the bivariate analyses. These variables were chosen based on previously published data $(2,3)$ and investigators' opinions of which are relevant to productivity. Explanatory variables for all models examined were age, sex (reference group: male), type of SSc (reference group: overlap), education, physician and patient overall health, HAQ DI, FACIT-F, and CES-D-10. Variables significant at $P$ values less than 0.10 in either model were entered into multivariable negative binomial regression models to assess predictors of days missed at work and days missed at home.

We also explored the predictors of disability due to SSc. We compared the group who reported that they are unable to work due to their SSc to patients who were currently employed. Explanatory variables for all models examined were age, sex (reference group: male), type of SSc (reference group: overlap), education, physician and patient overall health, HAQ DI, FACIT-F, and CES-D-10. Variables significant at $P$ values less than 0.10 were entered into the multivariable logistic model. All analyses were performed on Stata, version 10.2 , and $P$ values less than 0.05 were indicative of statistical significance.

Labor statistics. We calculated how the loss of productivity at work translated into 2010 US dollars. The US Department of Labor, Bureau of Labor Statistics recently published the median weekly earnings of employees ages 25 years and older by sex and level of education in 2010 (15). As an example, a woman with less than a high school diploma earned a median income of $\$ 377$ a week and a man with less than a high school diploma earned a median income of $\$ 485$ a week, whereas a woman with a bachelor's degree earned a median weekly income of $\$ 920$ and a man earned $\$ 1,138$. These weekly median values were multiplied by 52 and then divided by 12 (4.33) to obtain monthly estimated median earnings. We then calculated the estimated earnings lost due to work missed by multiplying estimated median earnings by the fraction of days of work missed per month to the total number of work days per month. As an example, for a woman earning a median income of $\$ 377$ a week, we calculated monthly income by multiplying $\$ 377 \times 4.33=\$ 1,632$. Taking $(52 \times 5) / 12=$ 22 to be the average number of work days per month, if this person missed 1 day per month, then the person lost an estimated $\$ 1,632 \times(1 / 22)=\$ 74$ a month. 


\begin{tabular}{|c|c|c|c|}
\hline & $\begin{array}{l}\text { Total } \\
\text { sample }\end{array}$ & lcSSc & dcSSc \\
\hline \multicolumn{4}{|l|}{ Employed outside of the home } \\
\hline $\mathrm{N}$ & $60+$ & 35 & 21 \\
\hline Nonmanual, no. (\%) & $41(68.3)$ & $22(62.9)$ & $16(76.2)$ \\
\hline Mixed, no. (\%) & $16(26.7)$ & $11(31.4)$ & $4(19.1)$ \\
\hline Manual, no. (\%) & $3(5.0)$ & $2(5.7)$ & $1(4.8)$ \\
\hline Work days missed (absenteeism), mean \pm SD & $2.6 \pm 6.3$ & $3.5 \pm 7.8$ & $1.5 \pm 2.9$ \\
\hline $\begin{array}{l}\text { Days with work productivity reduced by } \geq 50 \% \text { (presenteeism), } \\
\text { mean } \pm \text { SD }\end{array}$ & $2.5 \pm 6.1$ & $3.4 \pm 7.5$ & $1.2 \pm 2.6$ \\
\hline Days of SSc interference with work productivity, mean \pm SD & $2.2 \pm 2.9$ & $2.1 \pm 3.0$ & $2.7 \pm 2.9$ \\
\hline \multicolumn{4}{|l|}{ Not employed outside of the home } \\
\hline $\mathrm{N}$ & $99 \ddagger$ & 43 & 46 \\
\hline Homemaker, no. (\%) & $12(12.1)$ & $8(18.6)$ & $4(8.7)$ \\
\hline Retired, no. (\%) & $28(28.3)$ & $16(37.2)$ & $11(23.9)$ \\
\hline Student, no. (\%) & $5(5.05)$ & $3(7.0)$ & $1(2.2)$ \\
\hline Unable to work due to scleroderma, no. (\%) & $39(39.4)$ & $10(23.3)$ & $24(52.2)$ \\
\hline $\begin{array}{l}\text { Unable to work due to nonscleroderma health problems, } \\
\text { no. (\%) }\end{array}$ & $8(8.1)$ & $4(9.3)$ & $3(6.5)$ \\
\hline Other (i.e., volunteer work), no. (\%) & $4(4.0)$ & $2(4.7)$ & $1(2.2)$ \\
\hline Reported $>1$ category, no. $(\%) \S$ & $3(3.0)$ & $0(0.0)$ & $2(4.3)$ \\
\hline \multicolumn{4}{|l|}{ All patients } \\
\hline $\mathrm{N}$ & 164 & 83 & 67 \\
\hline Household work days missed, mean \pm SD & $8.0 \pm 10.6$ & $6.2 \pm 9.4$ & $10.9 \pm 11.8$ \\
\hline $\begin{array}{l}\text { Days with household work productivity reduced by } \geq 50 \% \text {, } \\
\text { mean } \pm \text { SD }\end{array}$ & $6.0 \pm 9.7$ & $5.5 \pm 9.5$ & $7.3 \pm 10.7$ \\
\hline $\begin{array}{l}\text { Days with family, social, and leisure activities missed, } \\
\text { mean } \pm \text { SD }\end{array}$ & $2.5 \pm 5.5$ & $2.4 \pm 5.6$ & $2.7 \pm 5.8$ \\
\hline Days with outside hired help due to SSc, mean \pm SD & $2.0 \pm 5.0$ & $1.4 \pm 4.0$ & $2.7 \pm 6.2$ \\
\hline $\begin{array}{l}\text { Days of SSc interference with household work productivity, } \\
\text { mean } \pm \text { SD }\end{array}$ & $4.0 \pm 3.4$ & $3.4 \pm 3.3$ & $5.1 \pm 3.5 \mathbb{I}$ \\
\hline \multicolumn{4}{|c|}{$\begin{array}{l}\text { * } \text { lcSSc }=\text { limited cutaneous systemic sclerosis (scleroderma); dcSSc }=\text { diffuse cutaneous systemic sclerosis. } \\
\text { † Four patients had overlap SSc. } \\
\text { \# Three patients did not report their status. } \\
\text { § One patient reported being retired and unable to work due to SSc; } 1 \text { patient reported being a student, unable to work due to SSc, unable to work due } \\
\text { to non-SSc health problems, and unable to work due to other reasons (i.e., volunteer work); and } 1 \text { patient reported being unable to work due to SSc } \\
\text { and unable to work due to non-SSc health problems. } \\
\text { II } P<0.05 \text {. }\end{array}$} \\
\hline
\end{tabular}

\section{RESULTS}

The mean \pm SD age of the patients was $51.8 \pm 14.2$ years and the mean \pm SD disease duration was $7.6 \pm 8.2$ years (Table 1). Eighty-one percent of our cohort was female, $69 \%$ were white, $52 \%$ had lcSSc, $41 \%$ had dcSSc, and $7 \%$ had overlap syndrome. Our patient cohort was well educated; $49.4 \%$ of our patients had at least a college degree. Patients with lcSSc were older in reported age (mean 56.0 versus 48.3 years; $P<0.05$ ) and had a longer disease duration (mean 9.3 versus 5.6 years; $P<0.05$ ). Patients with dcSSc had greater functional disability (1.3 versus $0.7 ; P<0.05$ ). There were no other differences in clinical characteristics (Table 1).

Sixty patients $(37 \%)$ were employed outside of the home, with a majority employed in nonmanual work (68\%) (Table 2). Of the 102 patients who were not employed outside of the home, $39.4 \%$ reported that they were unable to work due to SSc-related health problems (SScrelated work disability group), $8.1 \%$ were unable to work due to non-SSc health problems, $12.1 \%$ were homemakers, $28.3 \%$ were retired, and $5.1 \%$ were students. A higher proportion of patients with dcSSc $(76.2 \%)$ were employed in nonmanual work compared to lcSSc $(62.9 \%$; $P=$ not significant [NS]).

Work productivity in the employed patients. Employed patients $(n=60)$ reported missing 2.6 days per month of work (absenteeism), had 2.5 days per month of productivity reduced by half (presenteeism), and had 2.2 days per month where SSc interfered with their work (Table 2). Twenty-four (41\%) of the 58 (2 patients who were employed did not provide these data) employed patients missed at least 1 day of work per month. Patients with lcSSc reported missing more days of work (3.5 versus 1.5 days) and having more days with decreased productivity (3.4 versus 1.2 days) when compared to patients with diffuse disease ( $P=$ NS) (Table 2). We further compared patients doing manual/mixed work versus nonmanual work. Patients doing manual/mixed work had greater absenteeism (mean 3.95 days versus 2.03 days) and presenteeism (mean 4.0 days versus 1.74 days) compared to those doing nonmanual work, but this was not statistically significant $(P>0.05)$.

We explored the predictors of loss of productivity in the 


\begin{tabular}{|c|c|c|c|c|}
\hline & \multicolumn{2}{|c|}{$\begin{array}{l}\text { Work missed last month } \\
(\mathrm{n}=\mathbf{5 8}) \dagger\end{array}$} & \multicolumn{2}{|c|}{$\begin{array}{l}\text { Household work missed last } \\
\text { month }(\mathrm{n}=161) \neq\end{array}$} \\
\hline & $\begin{array}{c}\text { Unadjusted } \\
\text { coefficient }\end{array}$ & $\boldsymbol{P}$ & $\begin{array}{l}\text { Unadjusted } \\
\text { coefficient }\end{array}$ & $\boldsymbol{P}$ \\
\hline Age, years & 0.03 & 0.201 & -0.01 & 0.423 \\
\hline Male or female & 1.10 & 0.186 & 0.37 & 0.364 \\
\hline $\mathrm{lcSSc}_{\mathrm{C}}$ & 0.95 & 0.494 & 0.54 & 0.421 \\
\hline dcSSc§ & 0.14 & 0.925 & 1.11 & 0.099 \\
\hline Disease duration, years & -0.01 & 0.828 & -0.01 & 0.550 \\
\hline Education level & -1.32 & $<0.001$ & 0.04 & 0.780 \\
\hline Physician assessment & 0.58 & 0.002 & 0.22 & 0.010 \\
\hline Patient global assessment $\mathbb{I}$ & 1.96 & 0.011 & 1.62 & $<0.001$ \\
\hline HAQ DI & 1.74 & 0.011 & 1.16 & $<0.001$ \\
\hline FACIT-F & -0.10 & 0.001 & -0.07 & $<0.001$ \\
\hline CES-D-10 & 0.20 & 0.004 & 0.08 & 0.004 \\
\hline \multicolumn{5}{|c|}{ 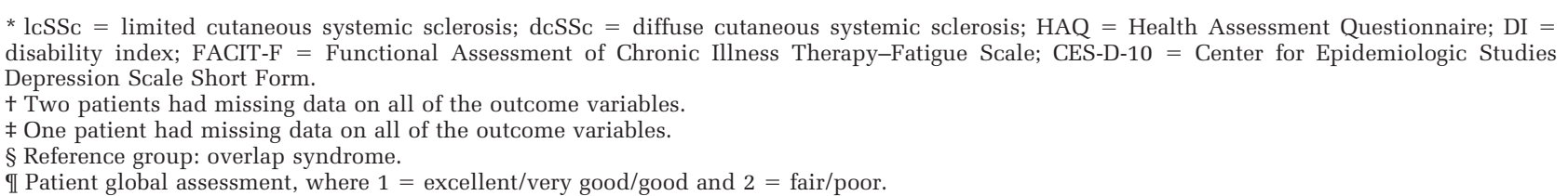 } \\
\hline
\end{tabular}

work place. In the univariate models, patients with a higher physician assessment of overall patient health (indicating poor overall health), a higher patient assessment of overall health (indicating poor health), higher HAQ DI and CES-D-10 scores (indicating greater functional and depressed mood, respectively), lower FACIT-F scores (indicating more fatigue), and lower education were more likely to miss work due to their SSc (Table 3). In the multivariate regression model, patients with lower education and poor health on physician assessment were more likely to miss work outside of the home (Table 4).

Household productivity in all patients. When assessing the entire patient population $(n=162)$, patients missed an average of 8 days of housework per month and had productivity reduced by more than $50 \%$ on 6 additional days per month (Table 2). SSc also had an impact on family and social activities, where patients missed an additional 2.5 days per month. Patients with lcSSc missed less days of household work than their dcSSc counterparts (6.2 versus 10.9 days; $P=$ NS) and had less days where their SSc interfered with household work (3.4 versus 5.1 days; $P<$ 0.05). Patients who were not employed missed more days of household work per month (8.9 days/month) than those who were employed (6.4 days/month; $P=\mathrm{NS}$ ).

In the univariate models, patients with poor overall health on physician assessment and patient assessment, higher HAQ DI (indicating more functional disability) and CES-D-10 scores (indicating greater depressed mood), and lower FACIT-F scores (indicating more fatigue) were likely to miss household work due to their SSc (Table 3). In the multivariate models, patients with lcSSc and high HAQ DI scores were more likely to miss work at home (Table 4). For example, for every increase in HAQ DI score by 1.0

Table 4. Multivariate regression models for productivity at work and home*

\begin{tabular}{|c|c|c|c|c|}
\hline & \multicolumn{2}{|c|}{$\begin{array}{l}\text { Work missed last month } \\
\left(n=49 ; \text { pseudo } R^{2}=0.15\right)\end{array}$} & \multicolumn{2}{|c|}{$\begin{array}{c}\text { Household work missed last } \\
\text { month }\left(n=135 ; \text { pseudo } R^{2}=0.05\right)\end{array}$} \\
\hline & Coefficient & $P$ & Coefficient & $\boldsymbol{P}$ \\
\hline lcSSct & -0.42 & 0.742 & 1.64 & 0.032 \\
\hline dcSSct & -1.33 & 0.317 & 1.10 & 0.143 \\
\hline Education level & -0.96 & 0.014 & 0.14 & 0.305 \\
\hline Physician assessment & 0.50 & 0.026 & -0.04 & 0.669 \\
\hline Patient global assessment & 0.84 & 0.300 & 0.91 & 0.073 \\
\hline HAQ DI & -0.07 & 0.929 & 1.03 & $<0.001$ \\
\hline FACIT-F & -0.04 & 0.420 & -0.03 & 0.097 \\
\hline CES-D-10 & -0.02 & 0.780 & 0.04 & 0.187 \\
\hline
\end{tabular}




\begin{tabular}{|c|c|c|c|c|}
\hline & \multicolumn{2}{|c|}{ Univariate model $(n=98)$} & \multicolumn{2}{|c|}{ Multivariate model $(n=81)$} \\
\hline & $\begin{array}{l}\text { Unadjusted } \\
\text { coefficient }\end{array}$ & $\boldsymbol{P}$ & $\begin{array}{c}\text { Unadjusted } \\
\text { coefficient }\end{array}$ & $\boldsymbol{P}$ \\
\hline Age, years & 0.99 & 0.703 & - & - \\
\hline Male or female & 0.93 & 0.898 & - & - \\
\hline lcSSct & 0.21 & 0.068 & 8.0 & 0.07 \\
\hline dcSSct & 0.90 & 0.898 & 1.6 & 0.5 \\
\hline Disease duration, years & 1.03 & 0.161 & - & - \\
\hline Education level & 0.50 & 0.001 & 0.51 & 0.01 \\
\hline Physician assessment & 1.53 & 0.001 & 1.27 & 0.16 \\
\hline Patient global assessment $¥$ & 10.74 & 0.025 & 2.43 & 0.48 \\
\hline HAQ DI & 6.09 & $<0.001$ & 5.22 & 0.01 \\
\hline FACIT-F & 0.92 & $<0.001$ & 0.99 & 0.89 \\
\hline CES-D-10 & 1.110 & 0.008 & 0.98 & 0.77 \\
\hline \multicolumn{5}{|c|}{$\begin{array}{l}\text { * Comparison is made between those patients reporting systemic sclerosis (SSc) disability versus those who reported being employed. One patient had } \\
\text { missing data on outcome variables and was not included in the univariate analysis. lcSSc = limited cutaneous SSc; dcSSc = diffuse cutaneous SSc; } \\
\text { HAQ = Health Assessment Questionnaire; DI = disability index; FACIT-F = Functional Assessment of Chronic Illness Therapy-Fatigue Scale; } \\
\text { CES-D-10= Center for Epidemiologic Studies Depression Scale Short Form. } \\
\text { † Reference group: overlap syndrome. } \\
\text { ‡ Patient global assessment, where } 1=\text { excellent/very good/good and } 2=\text { fair/poor. }\end{array}$} \\
\hline
\end{tabular}

unit, the household productivity decreased by 1 day after controlling for covariates.

SSc-related work disability. Thirty-nine patients reported disability due to their SSc. We explored the predictors of their disability when compared to patients who were employed. In the univariate model, significant predictors included lower education level, poor overall health on physician and patient assessments, higher HAQ DI scores, lower FACIT-F scores, and higher CES-D-10 scores (Table 5). In the multivariate model, higher HAQ DI scores were associated with greater odds of disability due to SSc, and higher education level was associated with greater odds of being employed.

Labor statistics in our cohort. Using recently published labor statistics, $41 \%$ of employed patients in our cohort missed at least 1 day of work per month, resulting in a mean income loss of $\$ 897$ (range $\$ 127-2,792$ ) per month. Patients with SSc-related disability (39.4\%) had a mean \pm SD income loss of $\$ 3,576.90 \pm \$ 1,302.80$ per month.

\section{DISCUSSION}

SSc is a chronic disease with marked decrements in functional disability and health-related quality of life that results in a significant burden to society (16). Our study shows that a lower education level and greater physician assessment of overall health are predictors of decreased productivity at work, lcSSc and higher HAQ DI score are associated with decreased home productivity, and lower education level and higher HAQ DI score are associated with SSc-related disability.

Although to our knowledge there are no studies that examine the predictors of decreased productivity in SSc using validated instruments, there have been studies in other rheumatic diseases. Kavanaugh et al used the WPS-RA and assessed productivity in RA in a clinical trial, and showed that impairment in physical function in RA negatively affects patients' productivity; patients have a limited ability to perform household and family activities and are dependent on outside help (7). Other studies have assessed productivity in different arthritides and are briefly discussed by Beaton and colleagues as proceedings from OMERACT 9 (5).

Previous studies have also shown that there is a substantial economic burden associated with SSc. The Canadian Scleroderma Research Group estimates that SSc costs up to 1.9 billion US dollars per year across Canada. They gathered information on the costs of medical care (direct costs), productivity loss (indirect costs), and total costs (direct and indirect costs combined) in 457 patients with SSc. They estimated productivity by using Statistics Canada's 1998 General Social Survey, which provides detailed time use of Canadians. Costs of lost productivity related to unpaid labor contributed \$8,070 Canadian dollars per patient annually in 2007 and accounted for $43.7 \%$ of the total annual cost per patient per year (2). They also found that high costs in SSc were strongly associated with greater disease severity, poorer health status, and younger age (2). The Canadian Scleroderma Research Group also found that lower education (i.e., no college education) was associated with greater costs overall, a trend that we also observed in our multivariate analyses. Total direct costs (i.e., the cost of all resources used in the medical treatment of SSc) were estimated to be $\$ 14,959$ (in 2007 Canadian dollars) per patient, with total indirect costs (i.e., productivity losses or gains attributable to morbidity or premature mortality from SSc) estimated to be $\$ 10,228$ per patient (3). Minier et al also conducted a cross-sectional study in Hungary to assess the costs of SSc and analyze cost drivers (16). Only $8.75 \%$ of patients were employed full time, with a majority $(48 \%)$ receiving a disability allowance. They showed that direct, indirect, and total costs were higher in patients with dcSSc compared to lcSSc. This increase in cost was attributed to a more frequent use of ambulance 
services by patients with dcSSc. Analysis of cost drivers demonstrated that disease activity had a significant impact on both direct and indirect costs, whereas disease severity and patient's perception of health status correlated only with direct costs. Hungarian official price, tariffs, and reimbursement lists of 2006 were used for cost calculation, and a validated instrument was not used to assess productivity. This group of researchers had previously assessed the cost of RA in Hungary, and found that SSc-related costs exceed the costs of RA (16).

In our cohort, $41 \%$ of employed patients missed at least 1 day of work per month, resulting in an average income loss of $\$ 897$ per month or $\$ 10,764$ per year (assuming patients missed same number of days each month for 48 weeks). These numbers are very similar to those assessed by the Canadian Scleroderma Research Group, where loss of productivity contributed $\$ 8,070$ Canadian dollars per patient annually in 2007.

One of the surprising results was a lack of association of functional disability and productivity at work. Previous studies in RA have suggested that the HAQ DI is an independent predictor of work disability. The HAQ DI has also been validated for the use of assessing work disability in SSc (17). In our cohort, low education and physician overall health assessment were associated with loss of productivity at work. It is possible that the lack of correlation with the HAQ DI is due to a well-educated cohort (68.3\% reported nonmanual employment), and physician assessment is a better reflection of disease severity and internal organ involvement. However, the HAQ DI did predict productivity at home. We expected dcSSc to be associated with decreased productivity at home, but noted that lcSSc was associated with poor productivity. This is likely related to the mean \pm SD older age group of our lcSSc patients of $56.0 \pm 14.1$ years versus $48.3 \pm 12.9$ years and greater disease duration compared to dcSSc $(P<0.05)$.

Our analysis also showed that greater HAQ DI score and poor education are associated with work disability. Ouimet et al conducted a cross-sectional study in Canada to estimate work disability in a cohort of patients with SSc and showed that HAQ DI score was the most important independent factor associated with work disability (4). They also showed that those with work disability had a longer disease duration and were more likely not to have completed high school. Hudson et al also conducted a similar analysis in a cross-sectional multicenter study of patients from the Canadian Scleroderma Research Group Registry (3). They found that patients with work disability were less likely to have education beyond high school and reported worse physical functioning as assessed by the HAQ DI.

Patient-reported inability to work had a significant impact on the patient's ability to earn income in our cohort. Although $84.4 \%$ of our patients had some college education, $39 \%$ of the cohort was unable to work due to SSc. This translated into a mean loss of $\$ 3,576.90$ per month or $\$ 42,922.80$ for 48 weeks of working time (assuming patients were disabled for 1 year).

Our study has noteworthy strength. To our knowledge, our study is the first to use a validated instrument to assess the impact of SSc on productivity outside of and in the home. We used a validated instrument to meet productivity in patients with SSc (5). Although we modified the instrument by replacing "arthritis" with "scleroderma," we believe that this does not diminish the psychometric properties of the WPS. Other researchers have only used employment statistics or societal surveys to assess productivity and have not used patient-reported outcome.

There are certain limitations to our study. Our findings are from a single scleroderma center and cannot be applied to the entire US SSc population. In particular, our patients were well educated and the societal impact may consequently be higher compared to other patients. Second, our study utilizes patient-reported outcomes, and we did not validate each individual patient's participation in household activities in face-to-face interviews. As an example, men who are disabled from work rarely become homemakers, and it is hard to extrapolate what kind of home-related activities they would participate in. Third, although we captured patient-reported inability to work based on the WPS, we did not validate the work disability, as our goal was to assess work productivity. Fourth, we did not collect any data on work history before entering into the cohort and therefore cannot assess if patients left work at some point prior to our study as a result of their disease. Lastly, we did not explore the cost of medical care due to SSc in our patient population.

In conclusion, SSc has a major impact on productivity at home and at work. Future studies should confirm our findings in larger cohorts and develop interventional programs to improve productivity at home and work in SSc.

\section{AUTHOR CONTRIBUTIONS}

All authors were involved in drafting the article or revising it critically for important intellectual content, and all authors approved the final version to be published. Dr. Khanna had full access to all of the data in the study and takes responsibility for the integrity of the data and the accuracy of the data analysis.

Study conception and design. Furst, Khanna.

Acquisition of data. Clements, Furst, Khanna.

Analysis and interpretation of data. Singh, Clements, Furst, Maranian, Khanna.

\section{REFERENCES}

1. Khanna D, Denton CP. Evidence-based management of rapidly progressing systemic sclerosis. Best Pract Res Clin Rheumatol 2010;24:387-400.

2. Bernatsky S, Hudson M, Panopalis P, Clarke AE, Pope J, LeClercq S, et al, and the Canadian Scleroderma Research Group. The cost of systemic sclerosis. Arthritis Rheum 2009; 61:119-23.

3. Hudson M, Steele R, Lu Y, Thombs BD, Canadian Scleroderma Research Group, Baron M. Work disability in systemic sclerosis. J Rheumatol 2009;36:2481-6.

4. Ouimet JM, Pope JE, Gutmanis I, Koval J. Work disability in scleroderma is greater than in rheumatoid arthritis and is predicted by high HAQ scores. Open Rheumatol J 2008;2:4452.

5. Beaton D, Bombardier C, Escorpizo R, Zhang W, Lacaille D, Boonen A, et al. Measuring worker productivity: frameworks and measures. J Rheumatol 2009;36:2100-9.

6. Escorpizo R, Bombardier C, Boonen A, Hazes JM, Lacaille D, Strand V, et al. Worker productivity outcome measures in arthritis. J Rheumatol 2007;34:1372-80.

7. Kavanaugh A, Smolen JS, Emery P, Purcaru O, Keystone E, 
Richard L, et al. Effect of certolizumab pegol with methotrexate on home and work place productivity and social activities in patients with active rheumatoid arthritis. Arthritis Rheum 2009;61:1592-600.

8. Osterhaus JT, Purcaru O, Richard L. Discriminant validity, responsiveness and reliability of the rheumatoid arthritisspecific Work Productivity Survey (WPS-RA). Arthritis Res Ther 2009;11:R73.

9. Frech T, Hays RD, Maranian P, Clements PJ, Furst DE, Khanna D. Prevalence and correlates of sleep disturbance in systemic sclerosis: results from the UCLA scleroderma quality of life study. Rheumatology (Oxford) 2011;50:1280-7.

10. Andresen EM, Malmgren JA, Carter WB, Patrick DL. Screening for depression in well older adults: evaluation of a short form of the CES-D (Center for Epidemiologic Studies Depression Scale). Am J Prev Med 1994;10:77-84.

11. Fries JF, Spitz P, Kraines RG, Holman HR. Measurement of patient outcome in arthritis. Arthritis Rheum 1980;23:13745.

12. Khanna D, Clements PJ, Postlethwaite AE, Furst DE. Does incorporation of aids and devices make a difference in the score of the Health Assessment Questionnaire-disability index? Analysis from a scleroderma clinical trial. J Rheumatol 2008;35:466-8.

13. Cella D, Yount S, Sorensen M, Chartash E, Sengupta N, Grober J. Validation of the Functional Assessment of Chronic Illness Therapy Fatigue Scale relative to other instrumentation in patients with rheumatoid arthritis. J Rheumatol 2005;35: 811-9.

14. Agresti A. A categorical data analysis. 2nd ed. New York: Wiley; 2002.

15. US Department of Labor, Bureau of Labor Statistics. Usual weekly earnings of wage and salary workers second quarter of 2010. 2010. URL: www.bls.gov.

16. Minier T, Pentek M, Brodszky V, Ecseki A, Karpati K, Polgar A. Cost-of-illness of patients with systemic sclerosis in a tertiary care centre. Rheumatology (Oxford) 2010;49:1920-8.

17. Clements PJ, Wong WK, Hurwitz EL, Furst DE, Mayes M, White B, et al. Correlates of the disability index of Health Assessment Questionnaire: a measure of functional impairment in systemic sclerosis. Arthritis Rheum 1999;42:237280. 